\title{
Peroxisome Biogenesis Disorder 5A
}

National Cancer Institute

\section{Source}

National Cancer Institute. Peroxisome Biogenesis Disorder 5A. NCI Thesaurus. Code C155756.

An autosomal recessive condition caused by mutation(s) in the PEX2 gene, encoding peroxisome biogenesis factor 2. Peroxisome biogenesis disorder 5A manifests phenotypically as Zellweger syndrome. 